\title{
Anisometropia in children: analysis of a hospital population
}

\author{
JELLE DE VRIES
}

From the Department of Ophthalmology, Erasmus University Rotterdam, Eye Hospital, Schiedamsevest 180, 3011 BH Rotterdam, The Netherlands

SUMMARY In a hospital population of 1356 children $64(4 \cdot 7 \%)$ cases of anisometropia (at least 2 dioptres in spherical or cylindrical power) were found. After the exclusion of all children with ocular lesions 53 remained. Twenty-seven $(42 \%)$ of them had strabismus, which seemed to be related to accommodation effort rather than amount of anisometropia. Amblyopia was present in $17(53 \%)$ of the patients with orthotropic anisometropia. Amblyopia increased with the amount of anisometropia. Therapy in the form of spectacle correction and part-time occlusion was successful in $47 \%$. The success rate was related to the age of presentation.

In the developing human eye anisometropia is considered to be a causal factor in the pathogenesis of amblyopia and strabismus. It is believed that 6 to $38 \%$ of all cases of amblyopia are caused by anisometropia without strabismus, ${ }^{12}$ whereas in about 12 to $18 \%$ of the children with strabismus this is accompanied by anisometropia. ${ }^{2-1}$

However, data on the prevalence of anisometropia and its complications in children are rare and divergent. The aim of this retrospective study was therefore to determine in a hospital population: the prevalence of the different forms of anisometropia, the prevalence of amblyopia or strabismus in combination with anisometropia, the changeability of anisometropia, and the results of treatment of anisometropic amblyopia.

\section{Patients and methods}

The archives of the Rotterdam Eye Hospital were screened for the records of anisometropic children born in 1972. Anisometropia was defined as a difference of 2 dioptres or more in spherical or cylindrical power between both eyes as determined by cycloplegic streak retinoscopy under either atropine $0.5 \%$ or cyclopentolate $1 \%$.

For children up to 6 years of age written instructions were given to all parents on how to instill $0 \cdot 5 \%$ atropine drops two hours prior to their appointment

Correspondence to Dr J de Vries, Oogziekenhuis, 3000 LM Rotterdam, Schiedamsevest 180, The Netherlands. and twice daily for the preceding two days. In older children $1 \%$ cyclopentolate drops were used: two drops with 5-minute interval 30 minutes prior to retinoscopy. The following data were recorded: age and reason for presentation, type and degree of anisometropia, best corrected visual acuity, ocular alignment, monocular fixation pattern, and accompanying signs or cause of anisometropia.

Five types of anisometropia were distinguished: anisohypermetropia, anisomyopia, mixed astigmatism, anisoastigmatism, and antimetropia. Patients were classified according to their most ametropic eye. The axis of any cylindrical component was classified as with-the-rule if the minus cylinder axis was within $15^{\circ}$ of $180^{\circ}$, against-the-rule for minus cylinder within $15^{\circ}$ of $90^{\circ}$, or oblique (i.e., other than with-or against-the-rule). The degree of anisometropia was expressed in spherical equivalents.

According to Jackson's suggestion ${ }^{5}$ not only the mathematical difference between the refraction of the two eyes but also the proportional difference was determined. The proportional amount of anisometropia was expressed in the ratio: anisometropia versus ametropia of the most emmetropic eye (for example, RE: -5 dioptres SE and LE: -3 dioptres SE proportional amount of anisometropia 2/3). In accordance with the child's maturity visual acuity was measured by using either picture targets, E hooks, or Snellen letters.

Since the results found on one scale are not quite comparable with those found on another, the amount 
of amblyopia and the improvement in vision under therapy have been expressed in a ratio using the visual acuity of the best eye as the denominator. Amblyopia was defined as visual acuity $<1.0(6 / 6)$ in the less good eye in combination with a ratio of 0.50 or less (e.g., visual acuity $1 \cdot 5(6 / 4)$ OD and $0 \cdot 3(6 / 20)$ OS, ratio 0.3/1.5). An improvement in vision of the amblyopic eye that increased the ratio 0.2 or more was considered a therapeutic success.

Wilcoxon's two-sample rank sum test was used to test significance.

\section{Results}

In January 1983 the archives of the Rotterdam Eye Hospital contained the records of 1356 children born in 1972. From these cases 64 cases of anisometropia (as defined previously) were obtained (4.7\%). Anisometropia ranged from 0.25 to 7.25 dioptres spherical equivalents. Forty-five had anisohypermetropia, 13 anisomyopia, and six mixed astigmatism. Cases of pure astigmatic anisometropia (i.e., only cylindrical differences) or antimetropia were not found.

With the exception of four all cases of anisohypermetropia and anisomyopia had an astigmatic component. The minus cylinder was with-the-rule in 42 , against-the-rule in five, and oblique in four patients, while in nine cases a combination was found.

Thirty-one patients first visited the Eye Hospital because of a (suspected) reduced visual acuity, 29 because of strabismus, and the remaining four for other reasons - namely, buphthalmos ( 2 cases), limbal dermoid as part of Goldenhar's syndrome, and trauma. There was an equal distribution between girls and boys.

The course of anisometropia was determined on the basis of data from all patients without ocular disease who underwent at least three retinoscopies $(n=27)$. In this connection the follow-up ranged from two to eight years, with a mean of four years.

The amount of anisometropia in spherical equivalents remained constant in 18 children, increased in five (mean $1.25 \mathrm{D}$, range 0.75 to 2.25 ) and decreased in four (mean $1.25 \mathrm{D}$, range 0.75 to 1.5 ). In other words anisometropia (as defined previously) arose in one and disappeared in another child.

After ophthalmological examination 27 patients were found to have strabismus, that is, 24 children with esotropia and three with exotropia. The remaining 37 patients had orthotropia as determined in the cover test by the absence of a fixation shift. However, since the monocular fixation pattern was not always mentioned in the record it could not be used as a standard to exclude cases of microtropia, as defined by Helveston and Von Noorden. ${ }^{6}$
Table 1 Comparison between children with orthotropic and heterotropic anisometropia

\begin{tabular}{|c|c|c|}
\hline & $\begin{array}{l}\text { Straight } \\
(n=32)\end{array}$ & $\begin{array}{l}\text { Strabismus } \\
(n=2 I)\end{array}$ \\
\hline Hypermetropia & 21 & 19 \\
\hline Myopia & 7 & 0 \\
\hline Mixed astigmatism* & 4 & 2 \\
\hline With-the-rule & 22 & 14 \\
\hline Against-the-rule & 1 & 2 \\
\hline Oblique & 2 & 1 \\
\hline Combination & 3 & 4 \\
\hline No astigmatism & 4 & 0 \\
\hline Amount of anisometropia & $2 \cdot 44 \pm 0 \cdot 50 \dagger$ & $1.95 \pm 0.42 \quad p>0.1$ \\
\hline $\begin{array}{l}\text { Amount of ametropia of } \\
\text { the most emmetropic cye }\end{array}$ & $2 \cdot 12 \pm 0 \cdot 56$ & $3 \cdot 03 \pm 0.86 \quad 0.05<p \leqslant 0 \cdot 1$ \\
\hline $\begin{array}{l}\text { Proportional amount of } \\
\text { anisometropia }\end{array}$ & $1 \cdot 77 \pm 0 \cdot 66$ & $1 \cdot 16 \pm 0.46 p>0 \cdot 1$ \\
\hline Age of presentation & $5 \cdot 53 \pm 0 \cdot 72$ & $3 \cdot 38 \pm 0 \cdot 74 p \leqslant 0 \cdot 001$ \\
\hline
\end{tabular}

${ }^{*}$ Cases of pure astigmatic anisometropia or antimetropia were not found.

†Mean \pm 2 SEM.

After the exclusion of all cases with ocular disease -namely, macular dystrophy cases, Brown's tendon sheath syndrome 2 , buphthalmos 2 , tilted disc, vasclar anomaly in the macula, Goldenhar's syndrome with limbal dermoid, keratoconus, and keratoconjunctivitis scrofulosa-the orthotropic and heterotropic groups were compared with each other (Table 1). The two groups differed as to type of anisometropia, degree of ametropia of the most emmetropic eye, and age of presentation.

\section{ORTHOTROPIC ANISOMETROPIA}

Thirty-two patients had orthotropic anisometropia without ocular disease. All of these children except two had a difference in best corrected visual acuity between both eyes. Amblyopia as defined previously was present in 17 of them and always occurred in the more ametropic eye. The group with amblyopia differed from the 15 other children in the amount of anisometropia $(0.1<\mathrm{p} \leqslant 0.02)$, which was greater in the former (mean \pm 2 SEM: 2.98 \pm 0.76 and $1.52 \pm 0.54$ dioptres spherical equivalents respectively). No significant difference could be demonstrated in the age of presentation, proportional amount of anisometropia, or amount of ametropia of the most emmetropic eye.

Amblyopia was treated with part-time occlusion (i.e., from waking until $4 \mathrm{pm}$ ) of the dominant eye preceded by the wearing of a spectacle correction for at least two months. In two patients occlusion therapy had to be abandoned because of noncooperation.

Under this regimen 11 children showed improvement in visual acuity of the amblyopic eye. Eight of 
Table 2 Therapy results in anisometropic amblyopia

\begin{tabular}{|c|c|c|c|c|c|c|c|c|c|}
\hline Patient & $\begin{array}{l}\text { Age of } \\
\text { presentation }\end{array}$ & $\begin{array}{l}\text { Amount of } \\
\text { anisometropia }\end{array}$ & $\begin{array}{l}\text { Ametropia of } \\
\text { the most } \\
\text { emmetropic } \\
\text { eye }\end{array}$ & $\begin{array}{l}\text { Proportional } \\
\text { amount of } \\
\text { anisometropia }\end{array}$ & $\begin{array}{l}\text { Visual acuity } \\
\text { of the } \\
\text { amblyopic eye }\end{array}$ & Ratio & $\begin{array}{l}\text { End visual } \\
\text { acuity }\end{array}$ & Ratio & Result $^{*}$ \\
\hline 1 & 4 & $2 \cdot 25$ & $3 \cdot 25$ & 0.75 & $0.25(6 / 24)$ & $0 \cdot 3$ & $0 \cdot 25(6 / 24)$ & $0 \cdot 25$ & $\mathbf{F}$ \\
\hline 2 & 2 & $4 \cdot 0$ & $2 \cdot 0$ & $2 \cdot 0$ & $0.5(6 / 12)$ & 0.5 & $0.7(6 / 8 \cdot 6)$ & 0.7 & $\mathbf{S}$ \\
\hline 3 & 3 & $4 \cdot()$ & $4 \cdot 25$ & $1 \cdot 0$ & $0 \cdot 1(6 / 60)$ & $0 \cdot 1$ & $1 \cdot 0(6 / 6)$ & $1 \cdot 0$ & $\mathbf{S}$ \\
\hline 5 & 9 & $5 \cdot 0$ & $1 \cdot 5$ & $3 \cdot 25$ & $0 \cdot 5(6 / 12)$ & 0.5 & $0 \cdot 5(6 / 12)$ & 0.5 & $\mathbf{F}$ \\
\hline 6 & 6 & $3 \cdot 75$ & $0 \cdot 25$ & 15 & $0.5(6 / 12)$ & 0.5 & $0.5(6 / 12)$ & 0.5 & $\mathbf{F}$ \\
\hline 7 & 6 & $3 \cdot 25$ & $2 \cdot 0$ & $1 \cdot 5$ & $0 \cdot 2(6 / 30)$ & $0 \cdot 2$ & $0.4(6 / 15)$ & 0.4 & $\mathbf{S}$ \\
\hline 8 & 6 & $1 \cdot 25$ & 0.75 & $1 \cdot 75$ & $0 \cdot 3(6 / 20)$ & $0 \cdot 3$ & $0 \cdot 25(6 / 24)$ & $0 \cdot 2$ & $\mathbf{F}$ \\
\hline 9 & 2 & 3.75 & $1 \cdot 0$ & $3 \cdot 75$ & $0 \cdot 5(6 / 12)$ & 0.5 & $1 \cdot 0(6 / 6)$ & $0 \cdot 65$ & $\mathbf{F}$ \\
\hline 10 & 9 & $2 \cdot 0$ & $6 \cdot 0$ & $0 \cdot 25$ & $0 \cdot 5(6 / 12)$ & 0.4 & $0 \cdot 6(6 / 10)$ & 0.5 & $\mathbf{F}$ \\
\hline 11 & 9 & $2 \cdot 0$ & $1 \cdot 25$ & $1 \cdot 5$ & $0.5(6 / 12)$ & 0.5 & $0 \cdot 8(6 / 7 \cdot 5)$ & 0.5 & $\mathbf{F}$ \\
\hline 12 & 4 & $3 \cdot 0$ & 3.75 & 0.75 & $0 \cdot 3(6 / 20)$ & $0 \cdot 3$ & $0 \cdot 8(6 / 7 \cdot 5)$ & 0.5 & $\mathbf{S}$ \\
\hline 14 & 8 & $7 \cdot 25$ & $1 \cdot 0$ & $7 \cdot 25$ & $0.25(6 / 24)$ & $0 \cdot 35$ & $0.4(6 / 15)$ & 0.5 & $\mathbf{F}$ \\
\hline 15 & 6 & 0.5 & $1 \cdot 75$ & 0.25 & $0 \cdot 5(6 / 12)$ & 0.5 & $0 \cdot 8(6 / 7 \cdot 5)$ & 0.5 & $\mathbf{F}$ \\
\hline 16 & 6 & $2 \cdot 5$ & $3 \cdot 0$ & 0.75 & $0 \cdot 5(6 / 12)$ & 0.5 & $1 \cdot 25(6 / 4 \cdot 8)$ & $1 \cdot 0$ & $\mathbf{S}$ \\
\hline 17 & 6 & $2 \cdot 75$ & $1 \cdot 0$ & $2 \cdot 75$ & $0 \cdot 5(6 / 12)$ & 0.5 & $1 \cdot 0(6 / 6)$ & 0.85 & $\mathbf{S}$ \\
\hline
\end{tabular}

${ }^{*} F=$ failure. $S=$ success.

them fulfilled the criteria of a therapeutic success, including one who was treated with a spectacle correction alone. Unfortunately, however, in three children the price of success was an occlusioninduced strabismus requiring surgical correction. The successful group differed from the other children only in regard to age of presentation $(0 \cdot 05<p \leqslant 0 \cdot 1)$, mean age $4.37 \pm 1.05$ and $6.55 \pm 1.63$ respectively (mean \pm 2 SEM). No difference was found in the amount of anisometropia, proportional amount of anisometropia, or ametropia of the most emmetropic eye (Table 2).

\section{Discussion}

In this study of a hospital population of 1356 children a prevalence of anisometropia of $4.7 \%$ was found. In a similar population of 5225 children 15 years of age and younger Phelps and Muir ${ }^{2}$ found a prevalence of $4 \%$. However, they defined anisometropia as a difference of 1.5 dioptres spherical equivalents or greater. It was also not clear whether or not cycloplegic retinoscopy was used. Ingram? found a prevalence of $2.7 \%$ in a general population of 1648 1 -year-old children. Anisometropia was defined as a difference of at least 1 dioptre in spherical or cylindrical power.

Laatikainen and Erkkilä" found a prevalence of $3.6 \%$ in 411 non-selected school children aged 7 to 15 years. They defined anisometropia as a difference of at least 1 dioptre spherical equivalent. Ingram ${ }^{7}$ also described a highly significant association between anisometropia, hypermetropia, and astigmatism. This fits in with our experience. Of the 64 patients with anisometropia 45 had anisohypermetropia, while 60 had an astigmatic component.

Very little is known about the stability or changeability of anisometropia in the developing human eye. A hypothetical process of emmetropisation was postulated long ago by Straub. ${ }^{9}$ However, many questions remain: does such a process actually exist or is it a mathematical artefact? Is it controlled by genetic or environmental factors, "' for instance, the wearing of spectacles? And is it a monocular or binocular process?

This study suggests that anisometropia is a rather stable condition. Although changes in the amount of anisometropia did occur, they were small and might be partly due to interobserver variation, since not all retinoscopies were performed by the same person. Ingram et al." recorded the appearance and disappearance of anisometropia (i.e., a difference of at least 1 dioptre in spherical or cylindrical power) between the ages of 1 and $31 / 2$.

In 27 children anisometropia was accompanied by strabismus $(42 \%)$. Phelps and $\mathrm{Muir}^{2}$ found this combination in $39 \%$ of cases. In the strabismus group the amount of ametropia of the most emmetropic eye was greater than that in the orthotropic group. This is in agreement with Phillips, ${ }^{12}$ who showed that the better eyes of non-squinting anisohypermetropes were significantly less ametropic than those of the squinting anisohypermetropes. In combination with the findings that myopia was not present in our strabismus group, that almost all children had esotropia, and that neither the amount of anisometropia nor the proportional amount of anisometropia differed from the orthotropic group, this 
suggests that the presence of strabismus is related to the accommodation effort rather than the anisometropia per se.

Almost all children with orthotropic anisometropia had a difference in best corrected visual acuity between both eyes, but about half of them had amblyopia, i.e., 17 out of $32(53 \%)$. By excluding all patients who did not meet Phelps's ${ }^{2}$ definition of amblyopia-namely, a difference of two lines or more on the Snellen chart or less than 0.5 vision in one eye-and anisometropia our figures are in close agreement with those found by him, 15 out of 25 $(60 \%)$ and 79 out of $132(60 \%)$ respectively.

The finding that amblyopia always occurred in the most ametropic eye is in agreement with data of other authors.' The observation that the amblyopic and 'normal' groups differed with respect to the amount of anisometropia supports the findings of Kivlin and Flynn ${ }^{13}$ who demonstrated a positive correlation between the amount of anisometropia and the depth of amblyopia.

Under our therapeutic regimen eight patients $(47 \%)$ with amblyopia were cured (therapeutic success). Sen's success rate was $64 \% .^{14}$ When his definition of anisometropic amblyopia (namely, anisohypermetropia, orthotropia, and visual acuity in the amblyopic eye of $\leqslant 0.5$ ) and therapy success (namely, improvement of at least 2 lines on the Snellen chart) were used, our success rate becomes $69 \%$ (9 out of 13 ). Kivlin and Flynn's success rate was $70 \% .{ }^{13}$ When their definitions of anisometropic amblyopia are used (namely, orthotropia and visual acuity in the amblyopic eye of less than 0.5 ) and therapy success (namely, endvision $\geqslant 0 \cdot 5(6 / 12)$ ), our success rate becomes $50 \%$ (4 out of 8 ).

In our opinion it is preferable to use a certain improvement in vision rather than an end vision of $0.5(6 / 12)$ as a criterion of success. The effect of measurement variation on the success rate is reduced, and it becomes possible to include cases with a visual acuity of $0.5(6 / 12)$ in the amblyopic eye.
Although several prognostic factors have been identified or suspected, such as age, depth of amblyopia, amount of anisometropia, therapy compliance, and accuracy of the optical correction, we could detect only the effect of age on our success rate.

In comparison with the results of other authors ${ }^{131516}$ our percentage of occlusion induced strabismus was high-i.e., $3-10 \%$ versus $20 \%$ ( 3 out of 15). Unfortunately, however, these authors do not describe their method of patching.

\section{References}

1 Flynn JT, Cassady JC. Current trends in amblyopic therapy. Trans Am Acad Ophthalmol Otolaryngol 1978; 85: 428-50.

2 Phelps WL, Muir V. Anisometropia and strabismus. Am Orthopt J 1977; 27: 131-3.

3 Crone RA, Velzeboer CMJ. Statistics on strabismus in the Amsterdam youth. Arch Ophthalmol 1956; 55: 455-70.

4 Stevens PR. Anisometropia and amblyopia. Br Orthopt J 1960; 17: 66-73.

5 Jackson CRS. Hypermetropic anisometropia. Br Orthopt J 1964; 21: 106-10.

6 Helveston EM, Von Noorden GK. Microtropia: a newly defined entity. Arch Ophthalmol 1967; 78: 272-81.

7 Ingram RM. Refraction of 1-year-old children after atropine cycloplegia. Br J Ophthalmol 1979; 63: 343-7.

8 Laatikainen L, Erkkilä $\mathrm{H}$. Refractive errors and ocular findings in school children. Acta Ophthalmol (Kbh) 1980; 58: 129-35.

9 Straub M. Ueber die Aetiologie der Brechungsanomalien des Auges und die Ursprung der Emmetroie. Albrecht von Graefes Arch Klin Ophthalmol 1909; 70: 130-99.

10 Michaels DD. Visual optics and refraction, a clinical approach. 2nd ed. St Louis: Mosby, 1980: 505.

11 Ingram RM, Traynar MJ, Walker C, Wilson JM. Screening for refractive errors at age 1 year: a pilot study. $\mathrm{Br} J$ Ophthalmol 1979; 63: 243-50.

12 Phillips CI. Strabismus, anisometropia, and amblyopia. $\mathrm{Br} \mathrm{J}$ Ophthalmol 1964; 43: 449-59.

13 Kivlin JD, Flynn JT. Therapy of anisometropic amblyopia. $J$ Pediatr Ophthalmol Strabismus 1981; 18: 47-56.

14 Sen DK. Results of treatment of anisohypermetropic amblyopia without strabismus. Br J Ophthalmol 1982; 66: 680-4.

15 Lewis BE. Anisometropic amblyopia. Br Orthopt J 1964; 21: 111-3.

16 Robinson J. Simple anisometropia and amblyopia. Br Orthopt J 1961; 18: 13-26. 